\title{
Sofrimento Mental e Dignidade da Pessoa Humana: Interpretando as Intercessões Históricas e Filosóficas da Ordem Psiquiátrica
}

\author{
Pedro Henrique Moreira da Silva \\ Mestre em Direito pela Escola Superior Dom Helder Câmara. Advogado e Professor de Direito. \\ http://lattes.cnpq.br/5242432989474760.https://orcid.org/0000-0002-8217-2169. pedroadvdireito@gmail.com

\section{Valdênia Geralda de Carvalho} \\ Doutora em Teoria do Estado e Direito Constitucional pela Pontifícia Universidade Católica do Rio de Janeiro (2017). Mestrado em \\ Direito pela Pontifícia Universidade Católica do Rio de Janeiro (2008). Graduação em Direito pela Pontifícia Universidade Católica de \\ Minas Gerais (1995). Diretora administrativo-financeira da Fundação Movimento Direito e Cidadania e Pró-Reitora de Pós-Graduação \\ da Escola Superior Dom Helder Câmara. Tem experiência na área de Direito, com ênfase em Direito Constitucional. \\ http://lattes.cnpq.br/2807932026067127.valdenia@domhelder.edu.br
}

A presente pesquisa propõe-se discutir a respeito da questão psiquiátrica, tanto pela perspectiva do transtorno mental quanto pelo ponto de vista do sofrimento mental - o que se faz pela pesquisa hipotético-dedutiva, baseada em material bibliográfico e documental. Nesse sentido, busca-se satisfazer objetivos-chave, tais quais a compreensão dos sentidos do sofrimento mental, a abordagem histórica da "loucura", a reflexão filosófica da lógica manicomial e dos recortes sociais e a explanação da psiquiatria democrática como alternativa aos padrões predatórios. Assim, resta viabilizada uma ótica ampliada da questão psiquiátrica, imperando a perspectiva humanista da tratativa do sujeito em sofrimento e a reflexão acerca da dignidade como elemento indissociável da pessoa humana.

Palavras-chave: Sofrimento mental. Dignidade da pessoa humana. Saúde mental. Reforma psiquiátrica.

MENTAL SUFFERING AND DIGNITY OF THE HUMAN PERSON:

INTERPRETING THE HISTORICAL AND PHILOSOPHICAL INTERCESSIONS OF THE PSYCHIATRIC ORDER

\section{ABSTRACT}

The research proposes to discuss about the psychiatric issue, both from the perspective of the mental disorder and from the perspective of mental suffering - which is done by hypothetical-deductive research, based on bibliographic and documentary material. In this sense, it is sought to satisfy key objects such as the understanding of the meanings of mental suffering, the historical approach to "madness", the philosophical reflection of the asylum logic and the social cuts and the explanation of democratic psychiatry as an alternative to predatory patterns. Thus, an extended perspective of the psychiatric question becomes feasible, with a humanistic perspective on the treatment of the suffering person and the reflection on dignity as an inseparable element of the human person.

Keywords: Mental suffering. Dignity of human person. Mental health. Psychiatric reform. SUMÁRIO

1 Introdução. 2 Da doença psiquiátrica e do sofrimento mental. 3 Evolução e recortes da percepção do "ser" homem na construção das relações psiquiátricas de poder. 4 Dignidade humana na perspectiva da psiquiatria democrática e da luta antimanicomial. 5 Considerações finais. 6 Referências. 


\section{INTRODUÇÃO}

O entendimento a respeito da questão psiquiátrica demanda a percepção de, no mínimo, duas vertentes de compreensão, estabelecidas entre a visão do "transtorno mental" e do "sofrimento mental". Trata-se de um tema que só pode ser satisfatoriamente estudado com uma pesquisa que perpasse as linhas biologista e histórico-social - esta última imprescindível ao entendimento da problemática por uma ótica baseada nos conceitos da dignidade e do humanismo. É justamente a esse propósito que atende o presente estudo, isto é, pretende-se demonstrar linhas duplas do entendimento do sofrimento mental, promovendo-se a explanação acerca do sofrimento mental e de sua tratativa no meio social.

Para tanto, inclui-se na discussão a lógica manicomial de punição, segregação e afastamento dos indivíduos "loucos", sem ignorar os recortes de classe, étnicos, sexuais e de gênero que marcam a problemática da "loucura". Isso se viabiliza pela pesquisa hipotético-dedutiva e pela interpretação das tratativas históricas da temática ao longo dos anos - o que se faz pelos recursos bibliográficos e documentais.

O esclarecimento da questão perpassa, portanto, pela satisfação de objetivos-chave, tais como a compreensão dos sentidos do transtorno e do sofrimento mental, a abordagem histórica da "loucura", a reflexão filosófica acerca da lógica manicomial e dos recortes sociais e a explanação a respeito da psiquiatria democrática como alternativa a um padrão predatório. A partir daí se justifica a pesquisa - seja pela compreensão do movimento de despersonalização da pessoa em sofrimento mental, seja pela urgência de resgate de um paradigma da dignidade que seja comum.

\section{DA DOENÇA PSIQUIÁTRICA E DO SOFRIMENTO MENTAL}

Antes que se adentre à temática proposta, faz-se necessário estabelecer a conceituação da "loucura" em duas vertentes, quais sejam, biologista e histórico-social. Dessa forma, será viável a problematização da dignidade e reconhecimento humano na dinâmica psiquiátrica, bem como constatar-se-á a lógica de poder que impregna a questão.

Nesse sentido a doença mental, em Dalgalarrondo (2008), é compreendida como

vivências, estados mentais e padrões comportamentais que apresentam, por um lado, uma especificidade psicológica (as vivências dos doentes mentais possuem dimensão própria, genuína, não sendo apenas "exageros" do normal) e, por outro, conexões complexas com a psicologia do normal (o mundo da doença mental não é um mundo totalmente estranho ao mundo das experiências psicológicas "normais").

Assim, doença mental, ao ser verificada no âmbito médico, corresponde à somatória de fatores biológicos e fatores psicológicos. Segundo afirma Brunton (2012), entre os fatores biológicos destacam-se desbalanços na quantidade de substâncias químicas cerebrais (como 5-HT, noradrenalina e dopamina, neurotransmissores cujo excesso ou falta estão envolvidos em grande parte dos transtornos mentais). Além disso, em Dalgalarrondo (2008) apreende-se a importância das alterações em estruturas encefálicas (por exemplo, no envolvimento das áreas cerebrais frontais no processo de delírio esquizofrênico). Com relação aos fatores psicológicos envolvidos, destacam-se os modelos psicanalíticos e psicodinâmicos, segundo os quais experiências subjetivas e simbólicas ao longo da vida de um indivíduo, especialmente na tenra idade, contribuem de maneira substancial na gênese dos transtornos mentais. 
A partir dessa concepção, sabe-se que existem diversas formas de acessar o sofrimento mental de um indivíduo no âmbito das ciências da saúde, tal como por meio da psicologia, da neurologia e da psicopatologia que, segundo Dalgalarrondo (2008), constitui uma forma de abordar o indivíduo "louco" a partir das considerações do "ser", compreendendo-se a extrapolação dos sinais e sintomas objetos de estudo da ciência médica.

Por outro lado, a partir de perspectiva histórico-social, verifica-se a possibilidade - e a necessidade - da construção de um paradigma que ultrapasse a conceituação patológica da questão mental. Assim, considerando-se as subjetividades do indivíduo, propõe-se o entendimento da doença psiquiátrica como sofrimento mental. Isto é, o homem "louco" perde o caráter de "homem-transtornado" para ser visualizado como "homem-em-sofrimento".

Note-se, a noção de sofrimento não perpassa pelo entendimento de sua condição mental como indesejável. Tão somente se reconhece que a vivência do ser humano fora dos padrões sociais é suficiente para caracterizar o sofrimento daquele que, por suas particularidades, não se adéqua à dinâmica artificial das relações humanas.

Dessa percepção conclui-se que a pesquisa acerca da saúde mental não pode se limitar à tecnicidade clínica, mas deve abordar os diferentes aspectos filosóficos e sociológicos dos transtornos. Referida investigação - acerca das relações sofrimento mental-comunidade e pessoa com sofrimento mental-comunidade - possibilita a conclusão a respeito do papel do ambiente social na construção dos transtornos mentais e na sustentação e criação de estigmas. A partir desses resultados restará a reflexão acerca dos processos de estabelecimento de critérios de normalidade, bem como da criação do entendimento do sujeito em tratamento psiquiátrico como sujeito de direitos - destinatário da dignidade da pessoa humana.

\section{EVOLUÇÃO E RECORTES DA PERCEPÇÃO DO “SER” HOMEM NA CONSTRUÇÃO DAS RELAÇÕES PSIQUIÁTRICAS DE PODER}

A análise da construção dos paradigmas psiquiátricos por meio da história confirma a transmutação da percepção da imagem da pessoa com sofrimento mental. Isto revela que os esforços medicinais para enquadramento ou reenquadramento de uma pessoa à realidade da saúde mental são abordagens modernas. Inclusive, vale relembrar que a própria essência do homem foi alterada ao longo dos anos, com a criação de novas visões sociais, o que ocasionou mutações nos conceitos de normalidade e anormalidade psiquiátrica.

Note-se, os caracteres determinantes da condição mental do ser humano não são inerentes à natureza do homo sapiens. Trata-se de construções de uma sociedade global que acumula legados históricos, religiosos, políticos, econômicos, sexuais e raciais. Dessa forma, inviável a abordagem de um ser humano que, naturalmente, pode ser enquadrado na lógica de indivíduos bem ou malsucedidos biologicamente - no que tange à psiquiatria.

Pelo contrário, a variação fisiológica e mental é retrato da pluralidade humana - em todas as suas formas. A dinâmica social, todavia, parte do pressuposto da setorização humana, de forma que são criados padrões artificiais de normalidade. Como praxe, os espécimes que não atendem às expectativas do sistema social são submetidos a processos de padronização, sob pena de terem negada a condição humana e a dignidade. 
Silveira e Braga (2005) confirmam a transmutação da percepção dos sofrimentos mentais ao relatarem que "inicialmente, por mais que pareça estranho aos olhos de hoje, pode-se afirmar que a experiência com a loucura nem sempre foi considerada algo negativo, muito menos uma doença. Pelo contrário, na Grécia antiga ela já foi considerada até mesmo um privilégio".

Naquele primeiro período da Antiguidade o sofrimento mental era entendido como manifestação divina, ou meio pelo qual o indivíduo delirante obtinha acesso às verdades dos deuses. Silveira e Braga (2005) ressaltam que o fascínio pela essência sacra conferida àqueles comportamentos não significava a aproximação e aceitação social daquelas pessoas. É que a própria divinização do estado mental requereu o distanciamento dos deuses e homens, Olimpo e Terra.

Essa percepção viria a ser invertida já na Idade Média, período em que a lógica cristã católica se instalou e iniciou os processos de demonização daquilo e daqueles que entendia indesejáveis aos padrões de homem cristão. Dessa forma, se outrora o portador de sofrimento mental era afastado da sociedade para conservar a essência dos deuses, no período medieval foi excluído por representar a encarnação e manifestação do mal.

Ali, ainda inexistia o objetivo social de reintegrar o indivíduo aos padrões de comportamento e personalidade da comunidade. O que se observa é que a associação das variações mentais com a figura maligna incentivou a dinâmica medieval do socorro religioso. Isso porque, estando o homem sob possessão de um inimigo espiritual, contraiu a Igreja para si o ônus da cura.

Não obstante, o advento da modernidade e da ciência iluminista trataria de romper com a lógica cristã na tratativa dos sofrimentos mentais. Naquele período, com a criação dos centros hospitalares, a "loucura" enfrentou uma abordagem em novo regime. Silveira e Braga (2005, p. 593) explicam que "para garantir seu funcionamento, o modelo hospitalar necessitava da instauração de medidas disciplinares que viessem garantir a nova ordem".

Isso implicava, portanto, na restrição de espaço físico e instauração de sistemas de vigilância para conter e supervisionar a nova figura do "louco" como indivíduo perigoso e antissocial. Foucault (2014) afirma que ali era um "lugar de confronto" e de poder, de forma que, ao mesmo tempo em que o modelo de hospital possibilitava a investigação, era também espaço de submissão. Isso porque o mesmo médico que dominava o diagnóstico pelo privilégio do conhecimento também era a figura responsável por criar a doença por meio de sua verdade e torná-la verdade ao paciente que lhe é submisso.

Nesse sentido, Foucault escreve:

Todas as técnicas ou procedimentos efetuados no asilo do século XIX - isolamento, interrogatório particular ou público, tratamentos, punições como a ducha, pregações morais, encorajamentos ou repreensões, disciplina rigorosa, trabalho obrigatório, recompensa, relações preferenciais entre o médico e alguns de seus doentes, relações de vassalagem, de posse, de domesticidade e às vezes de servidão entre doente e médico - tudo isto tinha por função fazer do personagem do médico o "mestre da loucura"; aquele que a faz se manifestar em sua verdade quando ela se esconde, quando permanece soterrada e silenciosa, e aquele que a domina, a acalma e a absorve depois de a ter sabiamente desencadeado (2014, p. 70). 
A pessoa com sofrimento mental é inserida, portanto, em uma lógica de poder. A dominação que a ela é imposta implica a produção de uma doença que lhe caiba pelos estereótipos e na vigilância constante, em razão dos perigos que a verdade patológica representa.

Vejamos: o modelo hospitalar do século 19 tratou de conferir ao médico o status de portador e orador da verdade medicinal. Isto é, dentro ou fora dos asilos psiquiátricos, o profissional sustentava o saber-poder, cujo instrumento é o próprio conhecimento. Ele, portanto, é legitimado a definir a essência do "louco" - cuja capacidade de se reconhecer não mais existe.

De forma didática, Foucault estabelece diálogo que bem exemplifica a questão:

Sabemos sobre a sua doença e sua singularidade coisas suficientes, das quais você nem sequer desconfia, para reconhecer que se trata de uma doença; mas desta doença conhecemos o bastante para saber que você não pode exercer sobre ela e em relação a ela nenhum direito. Sua loucura, nossa ciência permite que a chamemos doença e daí em diante, nós médicos estamos qualificados para intervir e diagnosticar uma loucura que Ihe impede de ser um doente como os outros: você será então um doente mental (2014, p. 73).

É nesse sentido que se constituiu a cultura perceptiva de aceitação da reclusão arbitrária da pessoa com sofrimento mental. Ora, a condição psiquiátrica dos indivíduos "despadronizados" retirou-Ihes a autonomia e, com fins de manutenção das relações de controle social, deslegitimou-os do próprio conhecimento.

Essa perspectiva carece de especial atenção, tendo em vista que ao paciente mental foi (e é) negado o status de persona, o que leva às justificativas dos métodos de acolhimento e tratamento e à própria supressão de dignidade. Isso porque a subjugação do "louco" implica a negativa de direitos fundamentais, relacionados à dignidade da pessoa humana.

Nesse ponto, vale invocar e interpretar os posicionamentos de Arendt (2001), no sentido de que a negativa da dignidade do homem "louco" perpassa pela negação de sua condição humana, antes e após a submissão aos métodos e locais de controle. Assim, são inviabilizados à pessoa com sofrimento mental o labor, o trabalho e a ação - trata-se da despersonalização do humano.

O labor é a atividade que corresponde ao processo biológico do corpo humano, cujos crescimento espontâneo, metabolismo e eventual declínio têm a ver com as necessidades vitais produzidas (...) a condição humana do labor é a própria vida. 0 trabalho é a atividade correspondente ao artificialismo da existência humana, existência esta não necessariamente contida no eterno ciclo vital da espécie, e cuja mortalidade não é compensada por este último. (...) A ação, a única atividade que se exerce diretamente entre os homens sem a mediação das coisas ou da matéria, corresponde à condição humana da pluralidade, ao fato de que homens, e não o Homem, vivem na Terra e habitam o mundo (ARENDT, 2001).

Dessa forma, ao ser enclausurado, o homem desviado dos padrões sociopsiquiátricos deixa de constituir o corpo social que lhe significa como humanidade. Isto é, considerando-se que "os homens são seres condicionados: tudo aquilo com o qual eles entram em contato torna-se imediatamente uma condição de sua existência" (ARENDT, 2001), o "ser" isolado nos hospitais psiquiátricos não só perde a capacidade de "ser persona", como também fica im- 
possibilitado de projetar sua condição humana no meio. Trata-se da construção de um "não ser" em um "não mundo", em que o paradigma da dignidade é inaplicável pela inexistência do próprio objeto, da negativa da problematização relembrada por Arendt (2001), a "quaestio mihi factus sum". ${ }^{1}$

Referenda-se a perspectiva supra também pela análise da vita activa, em Aristóteles e em Agostinho. No primeiro, porque a lógica manicomial impede a vida em ocupação do belo, "a vida voltada para os prazeres do corpo" (ARENDT, 2001); a vida em dedicação à polis; e a vida do filósofo, "dedicada à investigação e à contemplação das coisas eternas" (ARENDT, 2001). Assim, tal qual a vida do escravo na visão aristotélica, o homem "louco" não atende às premissas de ser e possuir a condição humana. No segundo - em Agostinho - porque a pessoa com sofrimento mental, ao ser submetida aos hospitais de internação, perde a capacidade de "engajamento ativo nas coisas deste mundo" (ARENDT, 2001).

A partir desse entendimento torna-se possível verificar que os hospitais psiquiátricos, para além de prisões e instituições para controle dos corpos, são dinamizados em um padrão de degradação da condição daqueles que ali se encontram - que não mais são pessoas humanas (ou não o foram nunca), portanto, passíveis de punição e tortura.

No Brasil pós-República essa concepção desdobrou-se no cenário que, nos termos de Daniela Arbex (2013), foi o "holocausto brasileiro". A significação do portador de sofrimento mental como "indesejável social" retirou-Ihe a própria garantia de ser e existir: aos "loucos", a vida enquanto for possível remediar; a morte como fim necessário de um ciclo indesejável.

Em razão dessa dinâmica de poder e submissão, a história psiquiátrica brasileira foi marcada pela indignidade no tratamento das pessoas com sofrimento mental, que vivenciaram condições análogas às dos campos de concentração nazistas. Daniela Arbex, realizando releitura da obra "Sorôco", de Guimarães Rosa, escreve que, aqueles pacientes, "ao receberem o passaporte para o hospital, (...) tinham sua humanidade confiscada" (ARBEX, 2013).

É justamente no livro de Arbex (2013), "Holocausto brasileiro", que se encontram variados relatos acerca das tratativas médicas dentro daquele que foi o maior hospital psiquiátrico do Brasil. Antônio Gomes da Silva, ex-paciente conduzido para o Hospital Colônia em 1969, ao ser entrevistado pela autora supracitada, relatou que desconhece os motivos pelos quais foi enviado ao hospital, tendo sido submetido à nudez constante e situações degradantes à moral: "Se existe inferno, o Colônia era esse lugar" (ARBEX, 2013) - aqui, note-se, a nudez se apresenta como consequência da desconsideração de uma das condições de "ser homem" em sociedade, qual seja, a vestimenta que possibilita a inserção do humano nos meios ordinários.

Geraldo Magela Franco, ex-vigia do hospital, e Ronaldo Simões Coelho, médico do Colônia, tratam de confirmar a questão quando de seus depoimentos a Arbex (2013), afirmando que os tratamentos de choque e as medicações assumiram, dentro do hospital, finalidades punitivas e não terapêuticas, confirmando-se a hipótese extraída da filosofia de Arendt. 


\section{Democracia}

Humanos e

A coisa era muito pior do que parece. Havia um total desinteresse pela sorte. Basta dizer que os eletrochoques eram dados indiscriminadamente. Às vezes, a energia elétrica da cidade não era suficiente para aguentar a carga. Muitos morriam, outros sofriam fraturas graves (ARBEX, 2013).

Assim, seja pela natureza das internações do Hospital Colônia, seja pelos tratamentos e punições aplicados aos pacientes, conclui-se pela negativa da condição de "ser" humano à pessoa com sofrimento mental - não sendo Homem, também não faz jus à dignidade do Homem, o que legitima seu afastamento da sociedade e tortura.

Nesse ponto, importa destacar que a questão da negativa do caráter de "persona" não é uma conduta aleatória. Trata-se de uma postura dos sistemas de poder, que vilipendia os princípios da República, na medida em que está impregnada de recortes socioeconômicos, étnicos, sexuais e de gênero.

Essa constatação permite dizer que os pobres, negros, LGBTQs e mulheres são seres mais propensos à submissão da lógica predatória psiquiátrica - desde a inauguração da Psiquiatria como Medicina. Seja pela vulnerabilidade social, seja pela ofensiva do sistema em silenciar essas comunidades, a própria condição étnica, cultural, social, sexual e de gênero é invocada como legitimadora da intervenção psiquiátrica - a condição subjetiva do ser homem como patologia.

A psiquiatria, ao tematizar questões importantes às estratégias de ordem social da República como os comportamentos sexuais, as relações de trabalho, a segurança pública, a questão racial e as manifestações políticas (Engels, 1999, p. 559), permitiu ao Estado brasileiro justificar cientificamente práticas de política social excludentes e segregadoras: destruição de cortiços, higienização das cidades e medidas sanitárias, repressão policial, internamentos (CUNHA, 1990; SEVCENKO, 2010, p. 82 apud SOARES, 2017).

A gênese, motivação e consequências desses recortes dentro da temática do sofrimento mental são distintas, de forma que importará à pesquisa promover análises apartadas - com desfecho na invocação da psiquiatria democrática como resposta à problemática da dinâmica de submissão psiquiátrica.

No que respeita ao recorte socioeconômico, cabe-nos relembrar que a naturalização da pobreza é questão datada da Antiguidade. Promoveu-se, desde lá, um padrão social pautado em diferenças econômicas e de desenvolvimento - fato que nos leva à consequência lógica de fortalecimento da dinâmica de privilégios dos detentores do poder e oneração do proletariado, que se intensificou na Revolução Industrial Inglesa.

Engels (2008), ao relatar as contradições socioeconômicas na Inglaterra industrial já explanava que

Liverpool, apesar do seu tráfego, do seu luxo e da sua riqueza, trata ainda os seus trabalhadores com a mesma barbaridade. Um bom quinto da população, ou seja, mais de 45.000 pessoas, habitam na cidade em casas exíguas, escuras e mal arejadas, em número de 7862 2S. A isto ainda se juntam 2.270 pátios, quer dizer, pequenos locais fechados pelos quatro lados, tendo como acesso e saída uma estreita passagem, frequentemente abobadada (que por conseguinte não permite o mais pequeno arejamento), a maior parte das vezes muito sujos e habitados quase exclusivamente por proletários (ENGELS, 2008, p. 69-70). 
Tal realidade reflete a negação da dignidade humana a partir da negação de moradia, saneamento básico, meio ambiente equilibrado, alimentação e saúde adequadas. Assim, ao ter negados os meios de produção, são retirados do proletariado também seus direitos fundamentais - o sistema trata de transfigurar o "ser" em "mão de obra". A consequência, portanto, é a negativa da humanização do proletário, cuja existência no mundo social é viabilizada tão somente enquanto durar sua capacidade de produzir.

Ultrapassada a capacidade laboral, o proletário é condenado às ruas e à miséria, assumindo a posição de indesejável social. Como tal, deve ser afastado do convívio comunitário e é justamente a esse papel que se presta a lógica psiquiátrica predatória. Nas ruas e nas periferias, a figura do homem pobre vilipendia as perspectivas do crescimento urbano e perturba o ambiente paisagístico. Ademais, sua sobrevivência apartada dos desejos capitalistas e do poder de consumo passa a ser verificado como perturbação da mente e do espírito - cria-se o homem "louco" que, ou sofre pela incompatibilidade social ou sofre em razão dos danos causados pelo sistema.

Assim, a condição de pobreza e miséria consolida-se como legitimadora da intervenção psiquiátrica. Note-se, mais que o desejo de adequar aquele homem aos padrões sociais, a internação do indivíduo em situação de miséria é método para retirar-lhe o contato social e, como verificado nos relatos de Arbex (2013), retirar-Ihe a vida.

Nesse ponto, importa afirmar que a experiência contra-hegemônica não perpassa pelo simplório impedimento do sequestro dos pobres em situação de miséria das ruas e periferias. Há que promover-se a ressignificação do proletariado como pessoa humana, efetivando-se o que Balera (1982) denomina de "Direito dos Pobres" - com disposição constitucional presente, mas ainda insuficientemente sólida. "Essas garantias visam, precipuamente, libertar os pobres das situações de miséria e de opressão a que são submetidos" (BALERA, 1982), de forma que o resgate da dignidade de vida resulta na própria contraofensiva à pretensão psiquiátrica de promover a retirada dos "indesejáveis" sociais do meio ambiente.

Nesse mesmo sentido se entrelaça a questão racial que, em Foucault (2014), apresenta-se como método de hierarquização dos corpos humanos para garantir benefícios a uns e mazelas a outros. O conceito de raça - controverso do ponto de vista dos direitos humanos - surge como pilar da biopolítica, alimentando e fortalecendo os padrões de legitimação da intervenção psiquiátrica. Explana Foucault (1999) acerca do tema:

É, primeiro, o meio de introduzir afinal, nesse domínio da vida de que o poder se incumbiu, um corte: o corte entre o que deve viver e o que deve morrer. No contínuo biológico da espécie humana, o aparecimento das raças, a distinção das raças, a hierarquia das raças, a qualificação de certas raças como boas e de outras, ao contrário, como inferiores, tudo isso vai ser uma maneira de fragmentar esse campo biológico de que o poder se incumbiu; uma maneira de defasar, no interior da população, uns grupos em relação aos outros.

Assim, ao estabelecer raças humanas, distinguindo-as pela cor e fenótipos, a ordem médica brasileira traçou contornos claros acerca de padrões não ideais que, em razão de sua inferioridade, estavam/estão mais sujeitos à intervenção. Foram estabelecidas características 
físicas que, por bastarem, já indicariam submissão - "a cor preta, platirhinismo (septo nasal largo), cabelo carapinhado, prograthismo, mais ou menos pronunciado (projeção das maxilas), lábios grossos e protahidos e pouca barba" (BARBOSA, 1992 apud SOARES, 2017).

Nesse contexto, conforme relembra Soares (2017), as publicações da Escola Médica do Rio de Janeiro não se constrangeram ao relatar que "a demência é a forma em que mais avulta os negros. Pode-se dizer que se tornam eles dementes com muito mais frequência, por sua constituição, que os brancos" (SOARES, 2017).

Ademais, o sofrimento mental foi também associado à miscigenação, de forma que a manifestação de sintomas como epilepsia indicavam ascendência negra - tratava-se de meio para desestimular relacionamentos afetivo-sexuais entre pessoas brancas e negras, com fins de "embranquecimento" social. É o que se nota nas constatações dos miscigenados como "um tipo mental sem valor, que não serve nem para o modo de viver da raça superior, nem para o da raça inferior, que não presta, enfim, para gênero algum de vida" (SOARES, 2017).

Assim, o negro passou a ser recolhido do meio social e trancado nos hospitais psiquiátricos, conforme bem leciona Carneiro (1993a) ao exemplificar que "em Salvador, o negro indigente, sofrendo de imbecilidade, de epilepsia e de outras moléstias mentais - como colocavam os discursos psiquiátricos - era capturado nas ruas e entregue às mãos do asilo psiquiátrico. Classificando-se o negro de insano, institucionalizava-se assim a exclusão" (CARNEIRO, 1993b apud SOARES, 2017).

Referida hipótese se confirma quando da análise dos dados acerca dos internados psiquiátricos no Brasil. Soares (2017) viabiliza a constatação de que os negros representavam, até 1920, dois terços da população sequestrada pelos hospitais psiquiátricos. E mais, a maior parte dos prontuários dos pacientes negros estava em branco, com menções breves de termos referentes à noção racial do humano - "beócio, primitivo, idiota, imbecilidade, débil mental" (SOARES, 2017).

Note-se, esses métodos de encarceramento (nos hospitais psiquiátricos) representaram a perpetuação da conduta escravocrata de restrição das liberdades, após a abolição. Isso porque, não servindo mais para o trabalho escravo - assim como o proletariado - o negro perde sua função no sistema, e como pessoa humana nunca foi, resta-lhe o extermínio em uma sociedade que reproduz a dinâmica dos poderes capitalistas.

Se, por um lado, o recorte socioeconômico e racial na psiquiatria está ligado às questões historicamente objetivas do sistema, o recorte sexual e de gênero impregna-se de subjetividades. Isso porque a ofensiva psiquiátrica à comunidade LGBTQ e às mulheres é também parte da violência estrutural do patriarcado.

Assim, conforme lecionam Zanella e Silva (2012) - e aplicando tal entendimento tanto à questão sexual quanto de gênero - são criados estigmas sociais para categorizar características valorizadas em cada sexo. "Nas mulheres foram encontrados o comportamento sexual marcado pela renúncia e pelo recato; traços de caráter relacionais, isto é, qualidades relacionadas à abnegação de si mesma e cuidado com os outros; e cuidado com o corpo, no sentido da busca de um ideal estético" (ZANELLA; SILVA, 2012). No caso dos LGBTQs, são esperados padrões de comportamento de supressão sexual e compensação da orientação sexual em ou- 
tras áreas sociais - no cuidado com o corpo, no sucesso acadêmico. O resultado, certamente, não é outro que a constatação de que as mulheres são até três vezes mais propensas à depressão que os homens, por exemplo (ZANELLA; SILVA, 2012).

Em um primeiro momento o discurso biológico trata de culpabilizar as próprias mulheres pelas mazelas que lhe são imputadas - a carga hormonal torna o corpo feminino propenso aos transtornos mentais. Da mesma forma, os LGBTQs têm a orientação sexual indicada como principal favorecedora do surgimento dos próprios transtornos. Não obstante, não se pode ignorar o entendimento de que o sofrimento mental, nesses casos, relaciona-se diretamente com os aspectos sociais e históricos. É o que confirmam Zanella e Silva (2012):

Em paralelo, a corrente sócio-histórica, preocupada com as condições materiais e existenciais que favorecem o sofrimento psíquico e seu agravamento, tem demonstrado quanto os fatores de risco relacionados à depressão são engendrados e sociais. Referem-se à maior pobreza, menores índices de alfabetização, rendas ínfimas, violência (física, sexual, verbal), etc. (ZANELLA; SILVA, 2012).

Essa realidade resulta em duas situações que, consequentemente, se seguem. Isso porque, ao desviar-se dos padrões delimitados pelo patriarcado, a mulher e a comunidade LGBTQ se inserem na dinâmica denominada por Zanella e Silva (2012) de hiperdiagnosticação: os corpos femininos e estranhos à lógica heterossexual que se atrevem a ser livres são os corpos "loucos" da sociedade. Assim, legitima-se o recolhimento nos hospitais psiquiátricos como forma de retirar-se do meio social figuras indesejáveis e intoleráveis que, em alguma medida, afrontam o sistema.

O "ser" mulher e o "ser" LGBTQ - tal qual ocorreu/ocorre com o "ser" negro - adentram o campo da patologia. É o que se confirma da classificação histórica da homossexualidade e transexualidade como transtornos mentais (notam-se avanços referentes à temática, com a retirada dos termos da lista de doenças psiquiátricas da Organização Mundial da Saúde).

É justamente da percepção dos recortes socioeconômicos, raciais, de gênero e sexualidade que se verifica o posicionamento da lógica psiquiátrica na sociedade. Isso porque construiu-se uma dinâmica de poder e controle dos corpos, recorrendo o sistema às internações nos "manicômios" como forma de remover os indesejáveis sociais do meio. Removê-los, note-se, não se confunde com recolhê-los para promoção da adequação à ordem. Trata-se de método para extermínio dessas comunidades, o que se faz pela modulação de condições inviáveis à vida dentro das instituições:

Péssima higiene do hospício, número insuficiente de funcionários, alimentação deficiente, precariedade das instalações, além das elevadas taxas de mortalidade por moléstias contagiantes como tuberculose e infecções gastrointestinais (...) o Juquery [por exemplo] constituiu-se como verdadeiro dispositivo de produção de mortes: dos 5.048 internos que aí foram deixados morrer, 59,23\% faleceram de fato, permanecendo em média 7,12 anos no Juquery (SOARES, 2017).

As relações de poder na ordem psiquiátrica fazem imperar, portanto, a desconsideração da humanidade e, consequentemente, a negação da dignidade, o que, nos termos de Delgado (1992), gera indignação e faz acender - sobretudo no Brasil, após 1980 - o movimento pela luta antimanicomial. Funda-se, nesse período, a contraofensiva à psiquiatria predatória - con- 
comitantemente à redemocratização do país - com novas possibilidade de entendimento e abordagem do sofrimento mental e, principalmente, com a inauguração da utopia que, em Basaglia (2005) e Delgado (1992), se denomina Psiquiatria Democrática, com fins de resgate do paradigma da Dignidade da Pessoa Humana - o objeto seguinte da pesquisa.

\section{DIGNIDADE HUMANA NA PERSPECTIVA DA PSIQUIATRIA DEMOCRÁTICA E DA LUTA ANTIMANICOMIAL}

O ensaio dessa guinada ocorre, conforme leciona Batista (2014), a partir da década de 50 do século 20, quando surgem correntes e abordagens da "loucura" pautadas na reforma terapêutica das instituições, extensão da psiquiatria ao espaço público e ruptura com os conceitos de loucura - seja pela antipsiquiatria, seja pela psiquiatria democrática. Esta última corrente, fortalecida pelos argumentos de Basaglia (2005), focava em uma tentativa de erradicar os manicômios, na medida em que passam a ser entendidos como uma instituição da violência nos moldes das prisões e escolas - baseados em autoridade opressiva e arbitrária, chantagem, exploração e ameaça. "O manicômio destrói o doente mental" (BASAGLIA, 2005).

Essa colocação se consolida, principalmente, pelo supracitado caráter discriminatório da caracterização da loucura.

Um esquizofrênico rico, internado em clínica particular, recebe um prognóstico diferente de um esquizofrênico pobre, encaminhado a um hospital psiquiátrico. O primeiro nunca é descontextualizado ou separado totalmente de sua realidade, o que facilita sua reinserção na sociedade. Os pobres seriam aqueles que já sofrem com a violência do sistema social (...) a exclusão dos loucos do mundo dos sãos só confirma e sanciona a validade das normas que a própria sociedade estabelece (BATISTA, 2014).

Assim, Basaglia (2005) propõe que a ação por uma psiquiatria democrática deve ser pautada em uma reviravolta institucional e científica, que nega a psiquiatria como forma de resolução de entraves sociais. Isto é, deve-se romper com a concepção de que aqueles que sofrem devem se adequar a uma sociedade viciada em suas condutas. A questão deixa de ser patológica para se tornar sociológica, na medida em que o problema da ordem psiquiátrica predatória é justamente a relação que estimula entre a sociedade e o "louco". Nesse contexto, o primeiro grande avanço no sentido de uma democratização da dinâmica psiquiátrica se esboçou na Itália, com a Lei Basaglia, quando se rompeu com a ideia inicial da internação obrigatória e se construiu uma proposta de tratamento obrigatório - o cuidado se sobrepondo aos hospitais asilares (BATISTA, 2014).

No Brasil, as primeiras propostas de rompimento com o padrão psiquiátrico punitivo foram delineadas no período de democratização, sobretudo pela articulação do Movimento dos Trabalhadores em Saúde Mental, que promoveu uma desarticulação da política de expansão e precarização dos asilos psiquiátricos. Ademais, a questão foi absorvida pelo debate acadêmico, de forma que se consolidou o Movimento da Luta Antimanicomial, com influência direta na legislação - no sentido de alternativas ao padrão da internação compulsória em asilos distantes do convívio social. Fontes (2012) trata de explanar que "a reforma psiquiátrica efetivamente começou a se materializar em serviços extra-hospitalares". A reforma psiquiátrica passa, nesse momento, a ser mais que uma utopia de rompimento com um modelo preda- 
tório, uma política de resgate e reformulação de paradigmas - a dignidade da pessoa humana ascendia na década de 80 como a coroa do ordenamento constitucional brasileiro, coroando também o projeto psiquiátrico.

Nesse sentido, como fim do movimento antimanicomial, a psiquiatria democrática modela-se como um ideal de resgate da condição de dignidade da pessoa com sofrimento mental, rompendo com um sistema que movimenta a exclusão e discriminação. Nesse ponto, a democracia aplicada à questão da "loucura" viabiliza o acolhimento em detrimento da exclusão e a construção de propostas de tratamento e aceitação da condição alheia ao padrão social solidificado em uma sociedade que adoece a si mesma ao desassociar a vida do outro do merecimento da dignidade - uma dignidade humana e comum.

\section{CONSIDERAÇÕES FINAIS}

Conforme se verifica da pesquisa, há possibilidade de se afirmar que a questão psiquiátrica pode ser visualizada sob dois aspectos. Um primeiro relacionando à condição mental como patologia de necessário tratamento, com justificativas para internação compulsória e afastamento do indivíduo da sociedade. Em um segundo aspecto, há possibilidade de visualizar a questão da condição mental como sofrimento mental, de forma que a pessoa passe a ser vista como parte vulnerável em uma sociedade baseada na lógica predatória - e que, portanto, merece e necessita ser cuidada e incluída.

Essa segunda perspectiva viabiliza o entendimento dos manicômios como instituições construídas para segregar e punir, de forma que o cuidado é secundário ou inexistente. Ademais, a própria dinâmica manicomial contribui e fortalece padrões segregacionistas, de forma que a questão da "loucura" amolda-se nas comunidades com relevante recorte de classe, etnia, sexo e sexualidade. Assim sendo, o transtorno mental - ou sofrimento, em uma visão mais humanista - é incorporado pelo sistema como instrumento para criação de indesejados sociais e promoção de seu afastamento do meio social. Nesse sentido, negros, mulheres, homens alheios aos padrões heteronormativos e pobres são tachados de "loucos" e aprisionados em recintos baseados na opressão e punição. A estes é negada a própria condição de persona e, consequentemente, a dignidade que lhes seria de direito.

É nesse contexto que a psiquiatria democrática surge como alternativa a um padrão baseado na máxima "vigiar e punir", segregar e afastar. A democratização da tratativa da pessoa com sofrimento mental perpassa por incluí-la no meio social e resgatar sua condição como humano - elemento indispensável à garantia de sua dignidade. É inegável que o fortalecimento da utopia nos anos 80 , com a influência nas políticas e leis é um avanço significativo. Não obstante, é indispensável manter a luta antimanicomial fortalecida como instrumento para alcançar novas conquistas e questionar os limites entre a existência de uma lógica de condição mental e a criação de um padrão que serve ao capitalismo, afastando indivíduos de sua inseparável coroação com a dignidade humana.

\section{REFERÊNCIAS}

ARBEX, D. Holocausto brasileiro. 20. ed. São Paulo: Geração Editorial, 2013.

ARENDT, H. A Condição Humana. 10. ed. Rio de Janeiro: Ed. Forense Universitária, 2001. 


\section{Humanos e \\ Democracia}

BASAGLIA, F. As instituições da violência. In: AMARANTE, P. (org.). Escritos selecionados em saúde mental e reforma psiquiátrica. Rio de Janeiro: Garamond, 2005.

BATISTA, M. D. G. Breve história da loucura, movimentos de contestação e reforma psiquiátrica na Itália, na França e no Brasil. Revista de Ciências Sociais, n. 40, p. 391-404, jan./abr. 2014.

BALERA, W. O Direito dos pobres. São Paulo: Edições Paulinas, 1982.

BARBOSA, R. M. Uma instituição modelar: o Hospício do Juquery. São Paulo: Fundação Seade, 1992.

BOBBIO, N. A era dos Direitos. Trad. Carlos Nelson Coutinho. 19. ed. Rio de Janeiro: Editora Campus, 1992.

BRUNTON, L. L. Goodman \& Gilman: as bases farmacológicas da terapêutica. 12. ed. São Paulo: AMGH Editora, 2012.

CARNEIRO, M. L. T. Negros, loucos negros. Revista USP, São Paulo, n. 18, p. 144-151, 1993 a.

CARNEIRO, M. L. T. Negros, II. Revista USP, Dossiê Brasil/África, São Paulo, n. 18, p. 144-151, 1993b.

CUNHA, M. C. P. Cidadelas da ordem: a doença mental na República. São Paulo: Brasiliense. 1990.

DALGALARRONDO, P. Psicopatologia e semiologia dos transtornos mentais. 2. ed. São Paulo: Editora Artmed, 2008.

DELGADO, P. G. As razões da tutela. Psiquiatria, justiça e cidadania do louco no Brasil. Rio de Janeiro: TeCorá. 1992.

ENGELS, F. A situação da classe trabalhadora na Inglaterra. 1. ed. São Paulo: Boitempo Editorial, 2008.

FONTES, E. M. M. As sete vidas da agenda pública em saúde mental no Brasil. Revista Estudos de Sociologia, Pernambuco, v. 1, n. 18. 2012. Disponível em: https://periodicos.ufpe.br/revistas/revsocio/article/ view/235235/28258. Acesso em: 23 jan. 2018.

FOUCAULT, M. Microfísica do poder. 28. ed. São Paulo: Editora Paz e Terra, 2014.

FOUCAULT, M. Em defesa da sociedade: curso no Collège de France (1975-1976). São Paulo: Martins Fontes, 1999.

FOUCAULT, M. Nascimento da biopolítica. Trad. Eduardo Brandão. 1. ed. São Paulo: Martins Fontes, 2008.

LIBERATO, M. D. Desinstitucionalizar é ultrapassar fronteiras sanitárias: o desafio da intersetorialidade e do trabalho em rede. Caderno Brasileiro de Saúde Mental, Santa Catarina, v. 1, n 1, p. 212-221, jan./abr. 2009. Disponível em: http://stat.ijkem.incubadora.ufsc.br/index.php/cbsm/article/view/1016/1142. Acesso em: 16 jan. 2018. LÜCHMANN, L. H.; RODRIGUES, J. O movimento antimanicomial no Brasil. Ciência \& Saúde Coletiva, v. 12, n. 2, p. 399-407, 2007. Disponível em: http://www.scielo.br/pdf/csc/v12n2/a16v12n2. Acesso em: 16 jan. 2018.

MINISTÉRIO DA SAÚDE. 2004. Residências terapêuticas. Disponível em: http://bvsms.saude.gov.br/bvs/publicacoes/120.pdf. Acesso em: 16 jan. 2018.

NAPOLI, M. Democracia, política, ciência e psiquiatria: o racismo como estratégia na sustentação do poder. Veredas do Direito, Belo Horizonte, v. 3, n. 6, p. 111-121, jul./dez. 2006.

SEVCENKO, N. A revolta da vacina: mentes insanas em corpos rebeldes. São Paulo: Cosac Naify, 2010.

SILVEIRA, L. C. BRAGA, V. A. B. Acerca do conceito de loucura e seus reflexos na assistência de saúde mental. Revista Latinoamericana de Enfermagem, Ribeirão Preto, v. 13, n. 4, jul./ago. 2005. Disponível em: http://www. revistas.usp.br/rlae/article/viewFile/2123/2212. Acesso em: 29 dez. 2017.

SOARES, S. A. Raça e psiquiatria: uma análise genealógica da questão racial na psiquiatria brasileira. Revista de Ciências Sociais, Fortaleza, v. 7, n. 2, p. 252-283, jul./dez. 2017.

ZANELLA, V.; SILVA, R. M. C. Saúde mental, gênero e violência estrutural. Revista Bioética, v. 20, n. 2, p. 267-279. 2012. Disponível em: https://periodicos.ufsm.br/seculoxxi/article/viewFile/31916/17578. Acesso em: 29 jul. 2018.

ZUARDI, A. W.; LOUREIRO, S. R. Semiologia psiquiátrica. Semiologia Especializada, Ribeirão Preto, v. 1, n. 29, p. 44-53, jan./mar. 1996. Disponível em: http://revista.fmrp.usp.br/1996/vol29n1/semiologia_psiquiatrica.pdf. Acesso em: 16 jan. 2018. 